Língua e poesia 



\title{
O último refúgio da língua geral no Brasil
}

\author{
EDUARDO DE ALMEIDA NAVARRO
}

\section{Introdução}

$\lambda{ }^{0}$

O CORAÇÃo da floresta amazônica, na mais preservada de suas regiões, o noroeste do Estado do Amazonas, livre do agronegócio, do garimpo e dos desmatamentos, é falada uma língua que participou intensamente da história da maior região do Brasil. Trata-se da Língua Geral, também conhecida como Nheengatu ou Tupi Moderno. Diferentemente de outras línguas que se poderiam classificar como línguas étnicas, por serem usadas somente por populações indígenas, a Língua Geral foi ali mais falada que o próprio Português, inclusive por não índios, até o ano de 1877, quando começava o Ciclo da Borracha. Língua-testemunho de um passado em que a Amazônia brasileira alargava seus territórios com o avanço das missões católicas e das tropas de resgate pelos vales dos seus grandes rios, a Língua Geral hoje é falada por mais de seis mil pessoas, num território que se estende pelo Brasil, pela Venezuela e pela Colômbia.

Essa língua supraétnica nasceu do Tupi Antigo, usado na maior parte da costa brasileira no tempo da chegada dos portugueses, em 1500. Os indígenas da costa que falavam variantes dialetais dele eram chamados genericamente de tupis. Eram eles os potiguaras, os tupinambás, os caetés, os tupiniquins, os tupis da Capitania de São Vicente etc. Os tupis eram considerados os antepassados de todos os índios da costa, segundo o jesuíta Simão de Vasconcelos.

Podemos dizer que o Tupi foi falado até o final do século XVII, após o que se foi transformando na Língua Geral, em seus dois principais ramos, a Amazônica e a Meridional. A Língua Geral Amazônica transformou-se, no século XIX, no Nheengatu. Ela começou a se formar no Maranhão e no Pará da língua falada pelos tupinambás que ali estavam e que foram aldeados pelos missionários jesuítas, juntamente com muitos outros índios de outros idiomas e etnias. A Língua Geral Meridional desapareceu completamente no início do século XX. Essa se irradiara a partir da Capitania de São Vicente para Minas Gerais, Goiás, Mato Grosso e para as capitanias do sul do país, seguindo o rastro dos paulistas que avançavam com suas entradas e bandeiras. Há indícios de que tenha também havido uma língua geral na costa leste do Brasil, no sul da Bahia. Com efeito, segundo Lobo et al. (2006),

em 1794, oficiais da Câmara e repúblicos da Vila de Olivença requereram a Antônio da Costa Camelo, ouvidor interino da Comarca dos Ilhéus, que provesse Manuel do Carmo de Jesus no cargo de Diretor de Índios, alegando, como 
maior razão para tal, ser [ele] criado naquela vila e saber a língua geral de índios para melhor saber ensinar.

A Língua Geral Amazônica foi aquela em que se expressou a civilização cabocla ribeirinha do Norte, que se definiu a partir da inserção dos índios no mundo do colonizador branco mediante sua escravização ou pela mestiçagem. Dezenas de povos indígenas diferentes a falaram. Índios de diferentes línguas e culturas conheciam-na. Foi por meio das línguas gerais que a América indígena encontrou-se com a América portuguesa. Elas representavam um encontro de mundos. Nascia, finalmente, o Brasil.

No século XVIII, na época pombalina, a Língua Geral Amazônica atingiu sua extensão máxima, falada do Maranhão até a fronteira com o Peru. Somente a partir daí ela passaria a desaparecer de quase toda aquela região. No início do século XIX ela não era mais falada em São Luís. Em 1876, o general Couto do Magalhães afirmava que ela estava morrendo em Belém do Pará.

\section{Fatores do desaparecimento da língua geral da maior parte da Amazônia}

Três fatores principais concorreram para isso. Foram eles os seguintes:

\section{As perseguições oficiais em meados do século XVIII}

Em 1750 sobe ao trono de Portugal D. José I. Seu poderoso ministro, Sebastião de Carvalho, o Marquês de Pombal, passa a aplicar uma política econômica e social que afetaria profundamente a história da Amazônia brasileira.

Era o século do Iluminismo. O projeto do governo português era ampliar o uso da língua portuguesa, fortalecer o Estado, inserir os índios na sociedade colonial e enfraquecer a Igreja, especialmente a sua principal ordem religiosa, a Companhia de Jesus. No Brasil, Pombal nomeia seu irmão Francisco Xavier de Mendonça Furtado para governador do Estado do Maranhão e Grão Pará (1751-1759). Esse governador iria promover a secularização da administração colonial. Empenhado na questão da demarcação das novas fronteiras entre os dois impérios, ele percorreu muitas partes da Amazônia. Enquanto isso, por razões estratégicas de Estado, substituiu os nomes indígenas dos povoamentos das margens de seus rios e atribuiu-lhes nomes portugueses. Foi assim que, na Amazônia, dezenas de vilas passaram a ter nomes de cidades portuguesas: Bragança, Alenquer, Faro, Óbidos, Santarém etc. O aldeamento de Mariuá, no Médio Rio Negro, passou a chamar-se Barcelos. Essa seria a sede da Capitania do Rio Negro, criada em 1757, a conselho do governador.

Em decreto de 6 de junho de 1755, retirava-se o poder temporal dos missionários. Suas atividades foram seriamente afetadas pela política do Marquês de Pombal. Eles perderam o controle da administração das aldeias, que então passaram a ser dirigidas por colonos, civis ou militares, que também ganharam o título de "diretores dos índios". Os missionários foram, todavia, autorizados a ficar nos povoados para prosseguir o trabalho de catequese e convencer os índios 
das cabeceiras dos rios e dos igarapés a virem instalar-se nas aldeias do médio e baixo Rio Negro. Ainda assim, ocorreu um sensível declínio do trabalho apostólico.

Na mal disfarçada intenção de apertar cada vez mais o cerco aos jesuítas, Pombal fez publicar, com data em 3 de maio de 1757, o célebre Diretório que se deve observar nas povoações dos indios do Pará e Maranhão, enquanto Sua Majestade não mandar o contrário. Esse Diretório procurou não apenas corrigir o inócuo alvará de 6 de junho de 1755, que entregara a jurisdição temporal aos próprios chefes indígenas, mas encaminhar visivelmente a expulsão dos jesuítas, os mais visados por esse documento.

\section{A morte de milhares de falantes de Nheengatu durante a Cabanagem}

Após a abdicação de D. Pedro I, em 1831, e sua partida para Portugal, o Brasil foi governado por regentes. Esses nove anos de governo regencial foram dos mais agitados de nossa história, época de verdadeiro caos político, especialmente pelo anseio de maior autonomia das províncias, designação antiga para os atuais Estados brasileiros. Algumas tinham fortes tendências federalistas e até separatistas. A república chegou a ser proclamada, por exemplo, na Bahia (com um movimento revolucionário conhecido como Sabinada, entre 1837 e 1838) e no Rio Grande do Sul (durante a Revolução Farroupilha, entre 1835 e 1845).

No Pará eclodiu a Cabanagem, o mais importante movimento popular da história do Brasil. Era uma explosão de sentimentos das massas pobres, exploradas durante séculos, porém não canalizados para a consecução de transformações econômicas e sociais que pudessem melhorar a vida dos mais desfavorecidos. Assim, em abril de 1836, os cabanos foram atacados por tropas imperiais. Belém e Barra do Rio Negro (a atual Manaus), tomadas pelos cabanos, são reconquistadas. Eduardo Angelim, o chefe da insurreição, foge e inicia-se grande perseguição aos cabanos em muitas partes da Amazônia, com grande violência por parte dos legalistas, com milhares de mortes daqueles. A repressão duraria três anos, com forte resistência dos rebeldes em vários lugares. Em 1839, para poder pôr cobro ao movimento, o governo regencial resolveu anistiar todos os participantes da Cabanagem.

Trinta mil caboclos e índios destribalizados morreram durante aquela insurreição, um quinto da população da província. A Língua Geral perdeu, assim, milhares de falantes, recebendo seu segundo grande golpe, após as perseguições de Pombal, no século XVIII.

As migrações de nordestinos para a Amazônia durante o Ciclo da Borracha

Apesar das suas severas perdas de falantes pelas razões já mostradas, a Língua Geral continuou a ser usada em grande parte da Amazônia ainda por várias décadas, superando largamente a língua portuguesa. Foi somente com as grandes migrações de nordestinos na década de 70 do século XIX que o Português se impôs como a língua dominante naquela região do Brasil, fazendo o Nheengatu ser língua minoritária. 
A emigração em larga escala começou com a grande seca de 1877, conhecida até os dias de hoje como "a seca dos dois setes". Foram três anos seguidos sem chuvas, sem colheitas, com a morte dos rebanhos, os homens fugindo para não morrer. Assim, a Amazônia, com o surto da borracha, oferecia-se como a salvação aos retirantes do sertão. Segundo Facó (1980), só em 1878 saíram do Ceará 120 mil pessoas, quando a população total da província era de pouco mais de oitocentos mil habitantes. Consigo levaram a língua portuguesa para a Amazônia, fazendo que, naquele ano, aquela passasse a ser a língua dominante naquela região.

\section{A literatura e a produção gramatical e lexicográfica em Língua Geral}

No último quartel do século XIX, quando a Língua Geral começava a se retirar de várias partes da Amazônia, vários autores, preocupados com esse fato, publicaram obras com o fito de registrar a língua que desaparecia e também de fortalecê-la onde ainda era falada. Havia um forte sentimento nativista e nacionalista subjacente a tais iniciativas. As principais obras dessa natureza impressas por brasileiros foram O selvagem, de Couto de Magalhães [1876], Grammatica da Lingua Brasileira (Brasilica, Tupi ou Nheengatu), de Pedro Luiz Sympson [1876], Poranduba Amazonense, de João Barbosa Rodrigues [1890], e Lendas em Nheengatu e em Português, de Antônio Brandão de Amorim [1928]. As duas primeiras foram publicadas como uma homenagem à passagem de D. Pedro II pela província do Pará no ano de 1876. Em seu discurso como membro da Assembleia Legislativa Provincial do Amazonas, Sympson (1926) escreveu: "Esta língua vernácula, que estava quase morta e perdida e a cujo estudo me dediquei como verdadeiro patriota, a fim de descobrir seus segredos, acha-se felizmente restabelecida por mim" (prólogo da $3^{\mathrm{a}}$ edição de 1876).

Além dessas obras da lavra de brasileiros, também as houve da autoria de estrangeiros nas últimas décadas do século XIX e nas primeiras do século XX. Essas foram Notes on the Lingua Geral or Modern Tupi of the Amazonas, do norte-americano Charles Frederik Hartt [1872], A Grammar and Vocabulary of the Tupi Language, do inglês John Luccock [1881], os Glossaria Linguarum Brasiliensium - Glossários de Diversas Linguas e Dialetos que falam os indios no Império do Brasil, do alemão Karl Von Martius [1867], La langue tapïhïya, dite tupi ou ñeengatú, do belga Constant Tastevin [1910], os Vocabulários de Lingua-Geral Português-Nheengatu e Nheengatu-Português, do italiano Ermano Stradelli [1929]. Contudo, essas obras não tiveram o condão de deter a retração do Nheengatu e seu desaparecimento de quase toda a Amazônia. Restaria somente a bacia do Rio Negro.

\section{A Língua Geral na Bacia do Rio Negro}

O Rio Negro é um dos maiores rios do mundo. Nasce na Venezuela, serve de divisa entre esse país e a Colômbia e entra no Brasil num ponto em que os três países se encontram numa tríplice fronteira, região conhecida como "Cabeça do Cachorro", o extremo noroeste do Brasil. 
Três são os municípios existentes ao longo de seu médio e alto curso: Barcelos (que foi também a primeira capital do Amazonas, antes chamada Província do Rio Negro), Santa Izabel e São Gabriel da Cachoeira. Juntas, suas populações perfazem cerca de cem mil pessoas, uma das menores e mais rarefeitas do país. A diocese de São Gabriel da Cachoeira, que tem à frente, hoje, o bispo D. Edson Damian, apresenta um território maior que o do Estado de São Paulo, a maior parte dele dominado por florestas.

Em São Gabriel já se avistam os contrafortes do Planalto das Guianas, onde estão as terras mais altas do Brasil, inclusive o famoso Pico da Neblina, o ponto culminante do país. Ali o Rio Negro já não permite a navegação de grandes embarcações e as linhas comerciais de transporte de passageiros já não mais existem. Os barcos carregados de passageiros, instalados em dezenas ou centenas de redes, fazem em três dias o percurso entre Manaus e aquela localidade remota.

São Gabriel é a cidade mais indígena do Brasil. Em suas ruas são faladas cerca de vinte línguas diferentes. É somente naquela região do país que ainda se pode ouvir falar a Língua Geral. Ela é o último refúgio do idioma que, no passado, impediu o domínio da língua portuguesa em grande parte da Amazônia.

A partir dos anos 30 do século XX, com a ditadura de Vargas, houve fortes iniciativas de fortalecimento da língua portuguesa na bacia do Rio Negro. As missões salesianas, as mais importantes do século passado naquela região, não incentivaram o uso do Nheengatu entre os seus educandos, sendo o emprego do Português obrigatório nos seus colégios. Os salesianos, por isso, em tempos passados foram acusados de etnocídio e levados ao Tribunal Internacional de Haia. Mesmo assim, houve publicações missionárias para a evangelização dos caboclos (por exemplo, um Pequeno Catecismo em Português e Nheengatu para uso das Missões Salesianas da Prelazia do Rio Negro, vindo ao prelo em 1944, em Manaus), além de publicações esparsas de diversas naturezas.

Por sua vez, durante o segundo governo de Getulio Vargas, de 1950 a 1954, tramitava no Congresso Nacional um projeto de lei que tornava obrigatória a criação da cadeira de Tupi em todas as faculdades de Filosofia, Ciências e Letras do Brasil. A repentina e trágica morte do presidente, em 24 de agosto de 1954, não frustrou os entusiastas de tal projeto: em 3 de setembro daquele ano, poucos dias após o suicídio do presidente, Café Filho, seu substituto naquele doloroso transe nacional, promulgava a Lei n.2.311, criando a cadeira de Etnografia Brasileira e Lingua Tupi naquelas faculdades.

A indefinição acerca do objeto dessa disciplina (Tupi Antigo ou Tupi Moderno?), gerou iniciativas díspares pelo Brasil. Em alguns lugares levou à criação de cadeiras de Tupi Antigo, noutros, à criação de cadeiras de Língua Geral Amazônica ou Nheengatu. Assim, a gramática de Nheengatu de Sympson recebeu novas edições nessa época para servir de texto básico para cursos que surgiam.

$\mathrm{Na}$ década de 70 do século XX, com o avanço de missões protestantes, patrocinadas por igrejas do exterior, especialmente dos Estados Unidos, viria 
ao prelo o Novo Testamento em Língua Geral, enriquecendo a literatura nessa língua. Foi, contudo, a partir da década de 1980 que vários pesquisadores estrangeiros do campo da Linguística e da Antropologia publicaram obras sobre o Nheengatu. Dessa fase são os seguintes trabalhos: Nheengatu (Lingua Geral Amazônica), Its History, and the Effects of Language Contact, de Denny Moore, Sidney Fagundes e Nádia Pires [1993], Pequeno Dicionário da Lingua Geral, de Françoise Grenand [1989] e Apontamentos sobve o Nheengatu falado no Rio Negro, Brasil, de Gerald Taylor [1988].

\section{Os fatores atuais de enfraquecimento do Nheengatu na Bacia do Rio Negro}

A modernização conservadora do Brasil correspondeu, na década de 1970, entre outras coisas, ao avanço da sociedade de consumo e da cultura de massas nas regiões mais afastadas dos grandes centros econômicos do país, como é o caso do Médio e Alto Rio Negro. Populações que, antes, viviam à margem do que ocorria nas grandes cidades do Brasil passaram, então, a ser afetadas por elas e a consumir seus produtos culturais e seus bens simbólicos, como as telenovelas, com os valores de uma classe média de São Paulo e Rio de Janeiro, as quais contribuíram para afrouxar os rígidos padrões de moralidade familiar estabelecidos pelas missões católicas, levando à desestruturação do mundo tradicional, com as inevitáveis consequências que todos conhecem: a droga, o alcoolismo, a prostituição, os divórcios etc. Juntamente com isso, ocorreu o êxodo das comunidades para as cidades, tornando ainda mais fácil o contato com a sociedade de consumo e com a língua portuguesa.

É claro que o vigor que a Língua Geral apresentava no Rio Negro até a década de 1970 devia-se também à precariedade da escolarização da infância e da juventude. As taxas de analfabetismo ali sempre foram altíssimas. Com efeito, o subdesenvolvimento econômico preserva mais tempo as culturas tradicionais e o Rio Negro era um bom exemplo disso até poucas décadas atrás.

No final dos anos 1990, veio a internet, o completo divórcio entre a comunicação e o espaço. Os mais afastados rincões do mundo, ainda que mal servidos por vias ou meios de transporte, são postos em contato em poucos segundos com o restante do planeta por meio dela e também da telefonia cada vez mais barata e da televisão, que já começam a chegar até as comunidades ribeirinhas mais distantes. Hoje, crianças e jovens das cidades às margens do Rio Negro apinham-se nas casas comerciais que oferecem serviços de computador para passarem horas a fio a se divertirem com jogos eletrônicos, um subproduto espúrio da cultura que a internet difunde.

Com tudo isso, a Língua Geral deixa, aos poucos, de ser falada pelas crianças e pelos mais jovens, que passam somente a entendê-la.

\section{As recentes iniciativas de revitalização da língua}

Em 2002, o município de São Gabriel da Cachoeira ficou conhecido por ter oficializado as três línguas indígenas mais usadas ali: o Nheengatu, o Baniua e 
o Tucano. Foi a primeira vez que outras línguas, além do Português, ascendiam à condição de línguas oficiais no Brasil. Contudo, a oficialização dessas línguas não teve os resultados que dela se esperavam. Redundou, porém, no ensino de Nheengatu nas escolas municipais daquele município e em muitas escolas estaduais nele situadas.

Em 2009 tomamos a iniciativa de criar tal disciplina na Universidade de São Paulo, a única cadeira universitária de Nheengatu no Brasil atual, como já era a de Tupi Antigo, existente ali desde 1935. Nem mesmo em Manaus existe estudo sistemático de Nheengatu nos dias de hoje.

Desde então, iniciamos um projeto de pesquisa intitulado por nós "Projeto Rio Negro", com o fito de elaborarmos um dicionário da Língua Geral que seja o mais completo até hoje já feito e que possa oferecer aos falantes do Nheengatu termos nativos que substituam as palavras portuguesas que têm sido cada vez mais usadas, fator de seu empobrecimento e decadência.

É fundamental que essa língua de tradição eminentemente oral tenha agora sua gramática estudada e que textos de diversas naturezas sejam escritos, justamente para enfrentar os novos tempos que chegaram, em que o contato com a língua portuguesa escrita acontece em toda aquela região.

Ao escrever o Nheengatu, deparamos, contudo, com a questão do sistema gráfico a ser adotado. Há posições conflitantes acerca da melhor forma de se escrever tal língua. De um lado, há os textos do final do século XIX e do começo do século XX, em que se grafa a Língua Geral sem se diferenciarem as vogais das semivogais, como faz o Português. Já alguns, influenciados pelo estruturalismo, passaram a grafar as semivogais com $y$ ou $w$, o que, a nosso ver, representa uma dificuldade a mais na aprendizagem da língua escrita, mormente por parte das crianças. Adotamos, assim, a ortografia tradicional, que simplifica ao máximo a grafia do Nheengatu.

Em 2011 publicamos um Curso de Lingua Geral, o segundo dessa natureza em anos recentes. Tomamos a iniciativa de distribuir gratuitamente milhares de volumes dessa obra pelas três cidades do Vale do Rio Negro onde o Nheengatu ainda é falado. No que tange às dezenas de comunidades ribeirinhas situadas em seus afluentes (Rio Xié, Rio Içana etc.) contamos com a ajuda do clero católico local. Com efeito, o apoio do bispado da diocese de São Gabriel da Cachoeira foi fundamental nesse aspecto.

Nosso Curso de Lingua Geral utiliza uma metodologia moderna de ensino de línguas, reunindo muitos exercícios escritos e incentivando a oralidade, em situações vivas e atuais. O livro porta também letras de canções em Nheengatu, gravadas por um grupo musical de São Gabriel, que já se prepara para produzir mais um $\mathrm{CD}$, que reúna, dessa feita, um maior número de canções naquela língua.

As próximas etapas de nosso trabalho serão as seguintes:

- Publicação de um curso de Nheengatu para as crianças já alfabetizadas e adolescentes, acompanhado de um CD. 
- Gravação de um CD que deverá acompanhar o nosso Curso de Língua Geral e a publicação de sua segunda edição.

- Divulgação de histórias em Nheengatu na internet, onde caboclos serão mostrados a contar fábulas e histórias.

- Publicação a preço baixo, para farta distribuição, de livros paradidáticos, que versem sobre a história e a geografia do Rio Negro e do Amazonas.

\section{Conclusões}

A tecnologia é paradoxal: pode servir ao mal e ao bem. Isso é também verdade no que tange às línguas ameaçadas de extinção. Nesse ponto, o Brasil é um dos países mais afetados. Seu recente surto desenvolvimentista, que levou milhões de pessoas a ascenderem a uma modesta, mas consumista classe média, afetou também as populações do Rio Negro. Hoje a televisão e a internet mudam rapidamente as mentalidades e as visões de mundo das pessoas. Ainda que à beira da floresta, populações remotas do Amazonas recebem a imagem dos paraísos do consumo burguês do Sudeste, sem instrumentos para uma reflexão crítica diante da imensa gama de informação que a atinge e que, ademais, é transmitida em Português. Mas se a tecnologia destrói o mundo tradicional, ela também se pode prestar muito bem à revitalização das línguas minoritárias. Com efeito, nunca houve na história tantos instrumentos eficientes de ensino de línguas como na atualidade. Nunca se pôde aprender tanto e tão bem como hoje o que quer que seja. Conhecimentos que, no passado, obtinham-se à custa de ingentes sacrifícios, hoje se conquistam com muita facilidade. Até mesmo línguas antigas como o copta, o geez, o aramaico, o siríaco etc. podem ser hoje aprendidas por meio da rede internacional de computadores. Aprimorou-se sobremaneira a didática das línguas e de tudo o mais. $\mathrm{O}$ ensino à distância já é uma realidade em diversos países.

Apesar dos riscos que corre, a Língua Geral acha-se em situação muito melhor que a maioria das línguas indígenas do Brasil, faladas por menos de quinhentas pessoas. O desafio, no entanto, é grande: em momentos de crescimento econômico, de acesso em massa da população mais pobre aos bens de consumo, muitos se deixam seduzir pela cultura da globalização e por suas benesses. Os argumentos ecológicos ou culturais passam a ser encarados como puro sentimentalismo diante dos argumentos do desenvolvimentismo. É assim que a usina de Belo Monte está sendo construída no Rio Xingu, com o apoio até mesmo de muitos povos indígenas. É assim que o inglês e a informática passam a ser muito mais atraentes aos jovens que preservar a língua e as tradições de seus ancestrais.

Mas o futuro do mundo sob o capitalismo já se torna cada vez mais incerto. A natureza já se vinga há tempos da sociedade de consumo e do american way of life que se espalhou por todo o planeta. Assim, muitos adquirem a consciência de que o mundo tradicional dos índios tem muito a dizer às sociedades do mundo atual. 


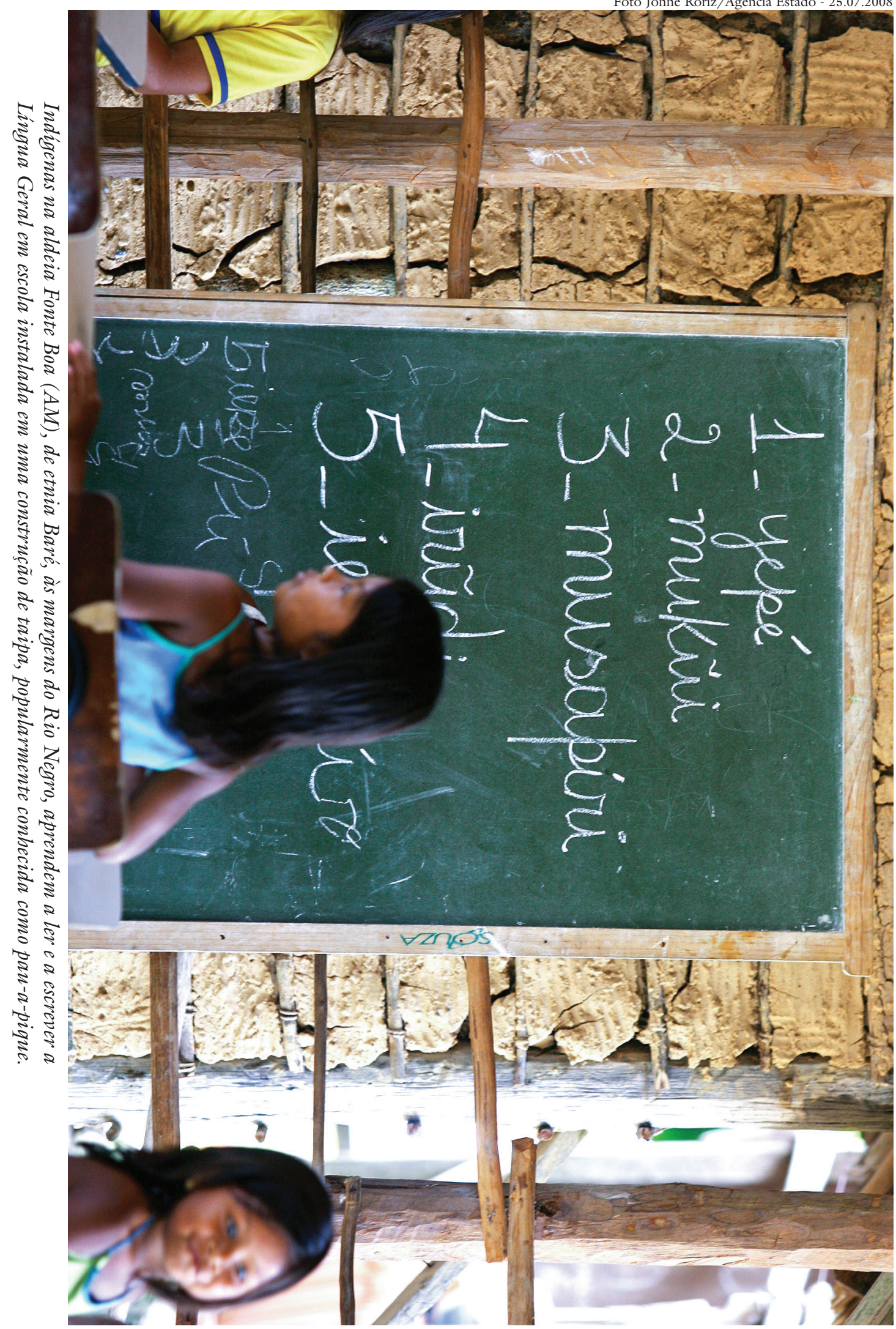




\section{Referências}

FACÓ, R. Cangaceiros e fanáticos. Rio de Janeiro: Civilização Brasileira, 1980.

LOBO, T. et al. Indícios de língua geral no Sul da Bahia na segunda metade do século XVIII. In: LOBO, T. et al. (Org.) Para a bistória do Português brasileiro. Salvador: EDUFBA, 2006. v.VI: Novos dados, novas análises, p.609-30.

SYMPSON, P. L. Grammática da Lingua Brasileira (Brasilica, Tupi ou Nheengatu). 3.ed, Rio de Janeiro: Fernandes, Neiva \& C., 1926.

RESUMO - Este artigo mostra a situação atual de uso da Língua Geral Amazônica, as causas de seu desaparecimento de grande parte do Norte do Brasil e as iniciativas atuais para sua revitalização.

PALAVRAS-CHAVES: Língua geral, Amazônia, Bacia do Rio Negro.

ABSTRACT - This paper focuses the present situation of Língua Geral Amazônica, the reasons for its extinction in most areas in Northern Brazil and the present efforts towards its revitalization.

KEYWORDS: Língua geral, Amazon, Negro River Basin.

Eduardo de Almeida Navarro é professor de Tupi Antigo e Língua Geral na Faculdade de Filosofia, Letras e Ciências Humanas da Universidade de São Paulo. @ - edalnava@yahoo.com.br

Recebido em 17.4.2012 e aceito em 18.4.2012. 